\title{
Mehr Zeit und Muße
}

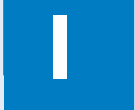

m Sommer dieses Jahres werde ich 60 Jahre alt. Schon vor längerer Zeit hatte ich den Entschluss gefasst, bei dieser Gelegenheit mein (Berufs-)Leben zu verändern. Ich liebe nämlich klare Daten.

Im Jahr 2006 starteten wir mit Krankenhaushygiene up2date - und zwar mit dem September-Heft. Mit diesem Juni-Heft sind nun 5 Jahre vergangen, in der sich die Zeitschrift als ein wichtiges Element zur Fortbildung in der Krankenhaushygiene in Deutschland etablieren konnte - und 5 Jahre sind wieder ein klarer Zeitraum bzw. eine runde Zahl. Es „passt“, wie man in Bayern sagt. Es passt also für mich, jetzt mit der Arbeit an der Zeitschrift aufzuhören, und darum geht es hier.

Der Beruf ist nicht alles. Das musste ich immer wieder feststellen, wenn ich mir gewünscht habe, dass doch der Tag 36 Stunden (oder so) haben möge. Es gibt hier in der Region diese einzigartige Natur, aber die Berge und Seen sind nicht nur zum Anschauen da. Solange ich fit bin, möchte ich sie näher kennenlernen. Es gibt aber auch Bücher, Sachbücher und Romane, die ich gerne lese, und es gibt die Menschen im privaten Umfeld. Ach ja, es gibt auch noch Muße und Langeweile. Beides kenne ich nicht mehr, und das ist nicht gut, meine ich. Für all das braucht man Zeit. Ich möchte mich also jetzt nach 6 Jahrzehnten Leben - beruflich wie privat - noch ein bisschen befreien, und deshalb trete ich nach dem ersten Halbjahr 2011 aus dem Herausgeberteam der Zeitschrift Krankenhaushygiene up2date aus, die mir jahrelang eine wichtige und zeitintensive Aufgabe war.

Ich möchte mich bedanken beim Thieme-Verlag für das Vertrauen, die Zeitschrift als leitende Herausgeberin zusammen mit den zunächst zwei, später drei Kollegen gestalten zu können, sowie bei meinen Kollegen für ihre Kreativität und Energie, die sie in den Aufbau und das Gelingen der Zeitschrift investiert haben. Insbesondere aber möchte ich mich bei den Lesern für ihr Interesse bedanken, denn ohne ihr Interesse wäre die Zeitschrift heute nicht mehr vorhanden. Sie ist es aber immer noch. Darüber freue ich mich nicht nur, sondern es bereitet mir regelrecht Vergnügen. Ich werde die Zeitschrift nun aus einer gewissen Distanz weiterhin wohlwollend begleiten, mit Interesse lesen und, wenn ich Zeit habe, vermutlich auch dann und wann einen Beitrag beisteuern.

Ines Kappstein 